\title{
Prospection inventaire dans le département de la Charente-Maritime
}

\section{Michel Favre}

\section{(2) OpenEdition Journals}

Édition électronique

URL : http://journals.openedition.org/adlfi/728

ISSN : 2114-0502

Éditeur

Ministère de la culture

Référence électronique

Michel Favre, "Prospection inventaire dans le département de la Charente-Maritime », ADLFI.

Archéologie de la France - Informations [En ligne], Poitou-Charentes, mis en ligne le 01 mars 2008

consulté le 26 avril 2019. URL : http://journals.openedition.org/adlfi/728

Ce document a été généré automatiquement le 26 avril 2019

(c) Ministère de la Culture et de la Communication, CNRS 


\title{
Prospection inventaire dans le département de la Charente- Maritime
}

\author{
Michel Favre
}

Identifiant de l'opération archéologique : 204485

Date de l'opération : 2008 (PI)

1 Au cours de l'année 2008, la prospection au sol permis la découverte de quatre-vingt-deux nouveaux sites archéologiques, sur l'ensemble de la Charente-Maritime, mais particulièrement dans l'est et le nord-est de ce département. Deux petites incursions doivent aussi être signalées hors Charente-Maritime, la première dans les Deux-Sèvres, où quatre sites furent découverts, l'autre en Charente, où un gisement fut également découvert.

2 Le haut Moyen Âge se retrouve sur quarante fiches dont trois concernent des ferriers; pour cette année, il s'agit de la période la mieux représentée. L'époque gallo-romaine apparaît sur trente fiches, le Néolithique sur dix-huit fiches, la protohistoire sur onze fiches, dont un site à sel implanté le long de la Gironde. Le Moyen Âge concerne dix fiches, le Badegoulien deux fiches et l'époque moderne une seule fiche, celle-ci se rapporte à une ancienne redoute construite à la fin $\mathrm{du} \mathrm{XVII}^{\mathrm{e}} \mathrm{s}$. pour surveiller une route et prévenir une éventuelle attaque contre l'arsenal de Rochefort.

FAVRE Michel 
INDEX

operation Prospection inventaire (PI)

Index chronologique : Empire romain, haut Moyen Âge, Néolithique, Protohistoire, Temps

Modernes

Index géographique : Poitou-Charentes, Charente-Maritime (17)

peuple Badegoulien

Thèmes : arsenal, bastion, défense, exploitation du sel, ferrier, route

\section{AUTEURS}

MICHEL FAVRE

BEN 